Mitteilungen der Österreichischen Geographischen Gesellschaft, 159. Jg. (Jahresband), Wien 2017, S. 348-358

\title{
Zum 200. Geburtstag des Verlegers Eduard Hölzel UND ZU SEINEN ANFÄNGEN IN OLMÜTZ ${ }^{1)}$
}

\author{
Petra KuBíČKOvÁ, Olmütz [Olomouc]*
}

mit 2 Abb. im Text

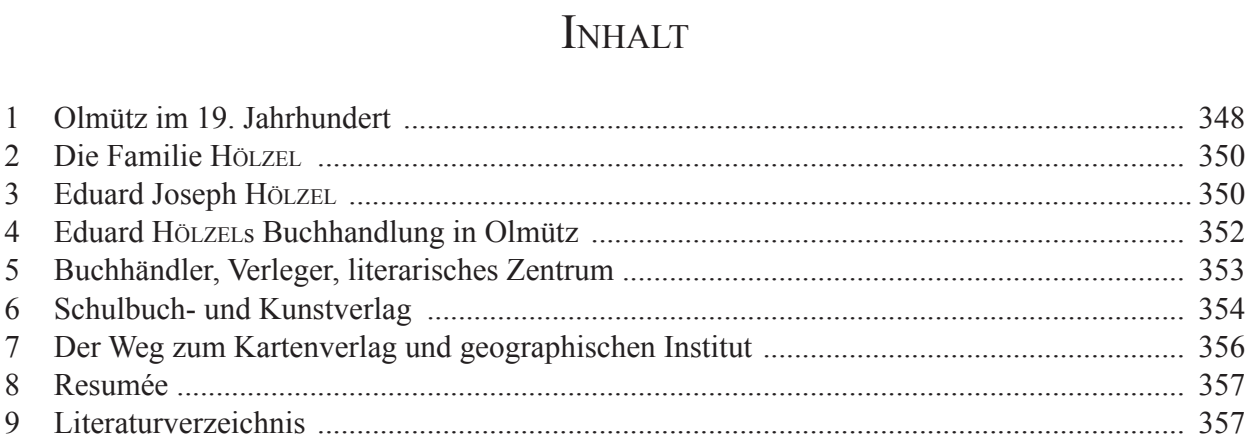

\section{Olmütz im 19. Jahrhundert}

Olmütz [Olomouc] gehörte im 19. Jh. zu den größten urbanen Zentren in Mähren [Morava]. Der Charakter der Stadt wurde außer von den allgemeinen politischen und wirtschaftlichen Verhältnissen durch ihre Bewohner geprägt, denn in Olmütz war nicht nur eine ziemlich große Garnison stationiert, sondern es lebten hier auch zahlreiche Geistliche und Studenten, und die Beamtenschaft wuchs ständig. Doch fehlte es der Stadt an größerer Industrie. Sie war vielmehr von einem landwirtschaftlichen Umland umgeben, das Bürgertum bestand überwiegend aus Gewerbetreibenden. Olmütz bildete ein bedeutendes Verwaltungszentrum Mährens. Es war Sitz von Ämtern der Staatsverwaltung, der Justiz und der Kirchenverwaltung, ebenso befanden sich hier auch verschiedene Bezirks- und Kreisämter. Es handelte sich zum Beispiel um das Kreisamt mit einem Kreishauptmann an der Spitze, um das Finanz- und Postamt, die Handels- und Gewerbekammer, das Kreisgericht, die Staatsanwaltschaft, das erzbischöfliche Konsistorium u.a. (Puš 2013).

Das politische Leben in der Stadt wurde seit der zweiten Hälfte des 19. Jhs. immer öfter durch nationale Streitigkeiten beeinflusst, welche eng mit der deutschen und tschechischen Politik in Ol-

1) Der Artikel beruht auf einem Beitrag aus dem Ausstellungskatalog „Eduard HöLzEL. 1817-1885“, der von der Wissenschaftlichen Bibliothek in Olmütz anlässlich des 200. Geburtstages von E. HöLzel veröffentlicht wurde.

* Mgr. Petra KuBíčKovÁ, Wissenschaftliche Bibliothek Olmütz [Vědecká knihovna v Olomouci], Bezručova 3, CZ-772 00 Olomouc 9, Tschechien; E-Mail: petra.kubickova@vkol.cz Der Artikel wurde von Jiří ČERNÝ aus dem Tschechischen übersetzt. 
mütz zusammenhingen und welche den tschechischen politischen Kampf innerhalb Österreichs widerspiegelten. Die deutsche Mehrheit herrschte über die Stadt bis 1918, aber beide Nationalitäten, sowohl die tschechische als auch die deutsche, ließen zahlreiche politische und kulturelle Organisationen und Vereine entstehen.

Die kulturelle Bedeutung von Olmütz ging über die Bezirksgrenzen hinaus, zahlreiche Persönlichkeiten aus den Bereichen der Politik, der Wissenschaft, der Kultur und Kunst wirkten in der Stadt, es erschienen hier viele Zeitungen und Zeitschriften, in Olmütz befanden sich Niederlassungen von verschiedenen Buchhandlungen, Verlagen und Druckereien.

Olmütz gehörte als die ursprüngliche Metropole von Mähren und als Bischofs- und Erzbischofssitz seit jeher zu den Kulturzentren der böhmischen Länder. Auch die Schließung der Universität im Jahre 1860 änderte nichts daran, weshalb sich im Laufe des 19. Jhs. sowohl polygraphische Industrie als auch Buchhandel erfolgreich entwickeln konnten (NEŠPOR 1936, S. 236). Es gab seit der ersten Hälfte des 19. Jhs. in Mähren zwei wichtige Zentren, in denen Verlags- und Buchhandelsfirmen versammelt waren: Brünn [Brno] und Olmütz.

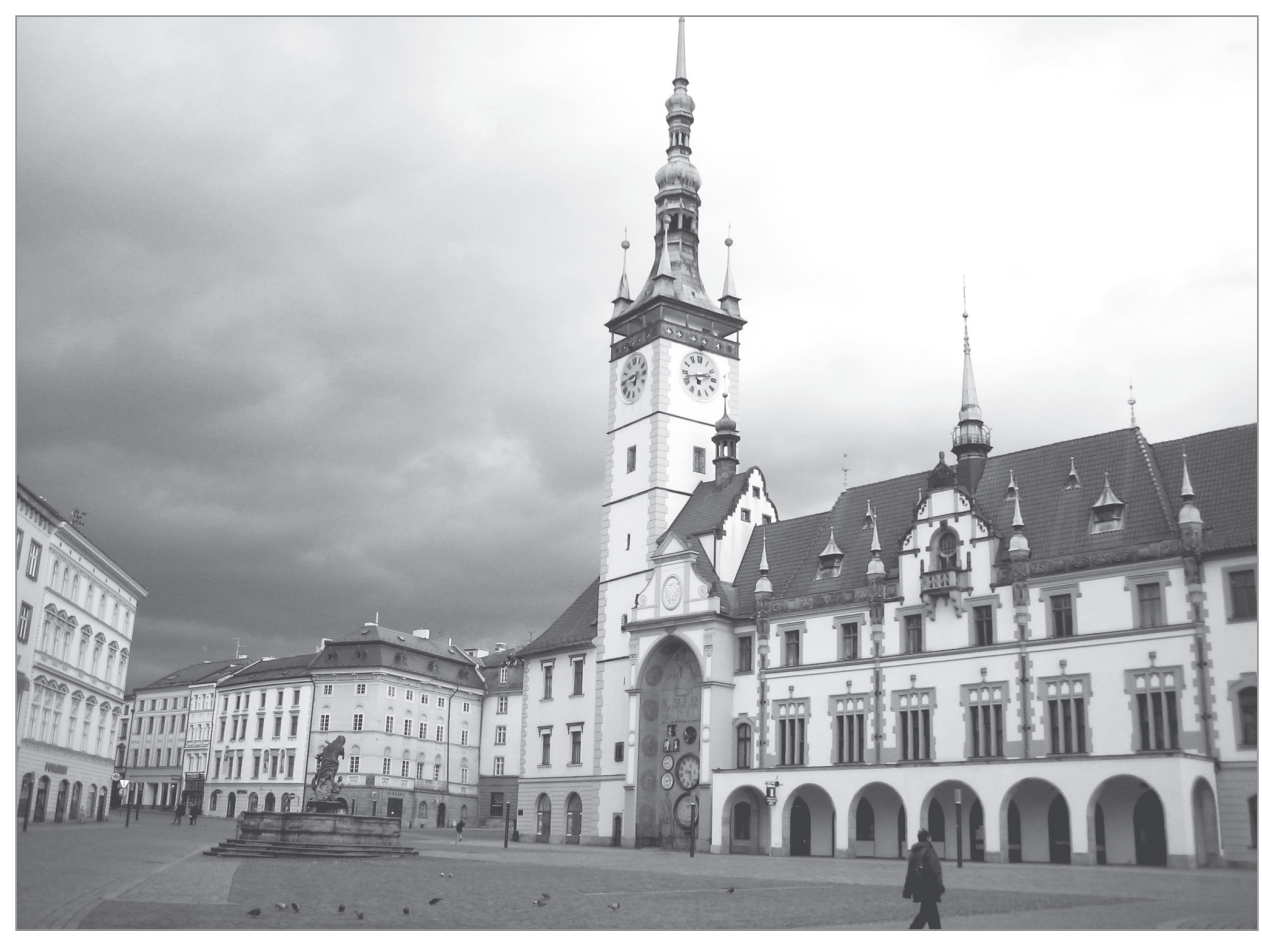

Foto: $\quad$ Peter JoRDAN 2008

Abb. 1: Der Obere Ring [Horní náměstí] in Olmütz [Olomouc]

Die Buchhandlung von Eduard HöLzel befand sich seit dem Jahre 1844 an der Nordseite des Oberen Ringes [Horní náměstí], des Hauptplatzes der Stadt (Abb. 1), welcher als Promenade für die höheren Gesellschaftskreise diente. Der Laden verfügte über verglaste Schaufenster rechts und links vom Eingang. Schon damals, noch bevor erste tschechische Buchhandlungen errichtet wurden, 
gedieh in dieser Stadt mit reicher Kulturtradition der Verkauf von deutsch-, aber auch tschechischsprachigen Büchern gut, und der Kreis von tschechischen - eher noch zweisprachigen - Lesern wuchs ständig an. Gefragt war sowohl Unterhaltungs- als auch Fachliteratur. Lehrbücher vieler Fachgebiete und auch Belletristik wurden eben in der Sortimentsbuchhandlung Eduard HöLzeLs angeboten, aus der sich allmählich eine der ersten wirklichen Fachbuchhandlungen in Mähren und ganz Österreich entwickelte.

\section{Die Familie HöLzel}

Man kann den Namen der Familie Hölzel (oder Höltzel) bis ins ausgehende 15. und beginnende 16. Jh. zurückverfolgen. Damals habe, wie in der Familie tradiert wurde, ein gewisser HöLzEL als Gehilfe bei dem Drucker, Verleger und Erfinder des Buchdrucks J. Gutenberg gearbeitet (Hölzel \& Lemmé 1933, S. 7). Petr Vort führt in seinem Nachschlagewerk Encyklopedie knihy einen Hieronymus HöLTzEL (gestorben etwa 1532) an, welcher ein Nürnberger Drucker war, also aus Bayern stammte, zum Beispiel für Albrecht Dürer arbeitete und im Kontakt mit dem böhmischen Raum stand (Vort 2008, S. 369). Im Stammbaum der Familie Hölzel sollen 37 Maler vorkommen, einige der Familienmitglieder hatten auch den adeligen Beinamen HÖLZEL VON HOLZ, HÖLZEL VON STEIN oder HöLZEL VON STOCK getragen (HöLzel \& LemMÉ 1933, S. 7).

Malerblut floss auch in den Adern von Eduards Vater Thomas Hölzel, welcher zwar ein Eisenwarenhändler vom Beruf war, sich aber viel lieber mit Kunst, Wandern und Sport beschäftigte. Thomas war ein hervorragender Geigenspieler, Zeichner und Maler, welcher seinem Freund und Erfinder der Lithografie Alois Senefelder Zeichnungen und Vorlagen für dessen Steindrucke lieferte (Hölzel \& Lemmé 1933, S. 8). Dieser Händler aus Prag [Praha] kümmerte sich also kaum um die Familienfirma und überlies deren Betrieb seiner Ehefrau Thekla, genauso wie den Prager Haushalt und die Pflege der gemeinsamen Kinder. Nach einem erzwungenen Verkauf der Firma zog Thomas HöLzEl zu seinem Sohn Eduard nach Brünn und zuletzt auch nach Olmütz, wo er verstarb. ${ }^{2)}$

\section{Eduard Joseph HöLzel}

Eduard Joseph HöLzel (Abb. 2) wurde am 8. Oktober 1817 in Prag geboren. Er war der älteste Sohn des schon genannten Johann Thomas HöLzel (1788-1846/ 47) und von Margarethe, geborene HerLth (1795-1823), die mit bloßen 28 Jahren verschied, als der kleine Eduard erst sechs Jahre alt war. Thekla Hölzel, geborene SrbovÁ, zweite Gattin von Thomas Hölzel, die einer reichen Brau-

\footnotetext{
2) Wir erfahren aus der Matrikel der römisch-katholischen Pfarre zu St. Michael in Olmütz, welche in der Olmützer Zweigstelle des Landesarchivs Troppau [Opava] [Zemský archiv v Opavě, pobočka Olomouc, ZAO-Ol] aufbewahrt wird, Einzelheiten über die Trauung von Eduard Hölzel. Seine Mutter ist in dem Dokument als Margarethe, geborene Herlth, eigetragen. (ZAO-Ol, Matriky, Sign. OV 12 1823-1860, Inv.Nr. 5643, Abb. 147, 26.2.1848). Auch der Eintrag in die Neue Deutsche Biographie (KINAUER 1972) sieht die Mutter von E. Hölzel in Margarethe Herlth, die in den Jahren 1795-1823 lebte. Im Archivkatalog des Archivs der Hauptstadt Prag (Archiv hlavního města Prahy, Schriftstück 304, Prager Angehörige, Thomas Hölzel, Karton Nr. 97, Verzeichnis aus dem Jahre 1830) figuriert Thekla als Ehefrau von Thomas HöLzel, von ihr spricht auch B. VybíRAL (1931, S. 141). Es werden unterschiedliche Lebensdaten von Thomas HöLzEL angegeben: Im Archivkatalog der Hauptstadt Prag wird angegeben, dass er im Jahre 1846 in Olmütz starb, die Deutsche Biographie gibt als Todesdatum das Jahr 1847 an, laut B. VyBíRAL sei er in Brünn um das Jahr 1840 verstorben.
} 


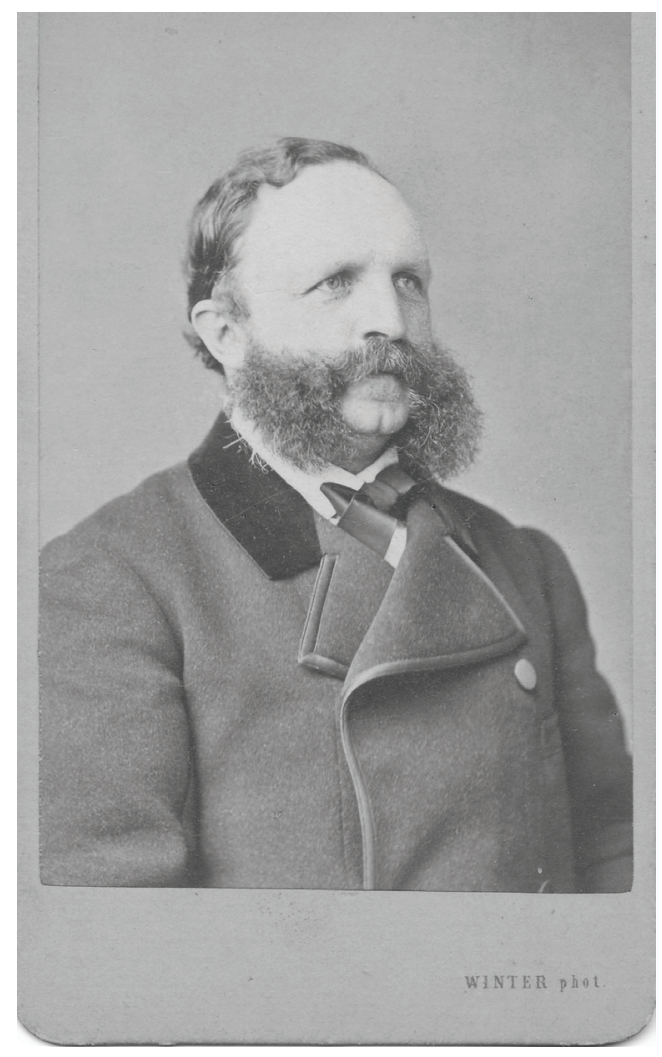

Foto: $\quad$ Atelier Winter, Wien, um 1870 (?). Archiv Ed. Hölzel

Abb. 2: Eduard Joseph Hölzel

meisterfamilie entstammte, zog dann Eduard und weitere fünf eigene Kinder groß. ${ }^{3)}$ Sie brachte allen ihren Nachkommen das Interesse für Bildung und Kultur bei, und ihr Stiefsohn Eduard gedachte ihrer in seinem Erwachsenenalter gern und mit Dank (VybíRAL 1931, S. 141). Nach dem Besuch der Volksschule und des Gymnasiums trat der junge Eduard in die Buchhandlung Borrosch \& André in Prag ein. Er bekam hier unter der Leitung von erfahrenen Buchhändlern die gehörige Schulung. Nach dem Abschluss der vierjährigen Lehrzeit fingen für HöLzel die Gesellenjahre an. Er arbeitete während dieser Zeit als Gehilfe in angesehenen Buchhandlungen in Leipzig, Mainz, Augsburg, Würzburg, Wien und Brünn (LindEMANN 1899).

Eduard Joseph HöLzEL entschied sich, aus seiner letzten Wirkungsstätte Brünn nach Olmütz umzuziehen. Somit begab er sich in eine Stadt, in der er niemanden kannte, von welcher er aber

3) Bruder Heinrich (geb. 1827) erlernte auch den Buchhändlerberuf, der andere Bruder hieß Ernst (geb. 1830); die Namen der Schwestern waren Marie, Mathilde und Emma. Mathilde wurde Opernsängerin, Emma war zweite Ehefrau von Romuald Promberger d.Ä., zu seiner dritten Gattin wurde nach dem Tod deren Schwester Marie, welche den Sohn Romuald Promberger d.J. gebar, den künftigen Verleger von Olmütz (Vybíral 1931, S. 139). 
annahm, dass sie trotz bestehender Konkurrenz ein günstiger Ort für eine neue Buchhandlung sein könnte. Angesichts der beschränkten finanziellen Möglichkeiten von HöLzel hätte es sich um einen mehr als riskanten Schritt handeln können. Eduard sah aber trotz aller Hindernisse in Olmütz ein gewisses Potenzial. Einerseits befanden sich hier viel weniger Buchläden als zum Beispiel in Brünn, anderseits war die Stadt eine mährische Metropole, in welcher der Erzbischof und eine Universität ihren Sitz hatten. Hölzel war sich überdies der günstigen Lage von Olmütz bewusst. Weil es fast inmitten Mährens lag, bot es ideale Möglichkeiten, das Geschäft auf ganz Nordmähren [Severní Morava] auszuweiten. Das sind Gründe, welche Eduard HöLzel auch in seinem Zirkular für das Landesgubernium von 25. September 1844 nannte, wo er außerdem zugab, dass er an das Eröffnen seines eigenen Ladens etwa seit 1831 gedacht hatte, also seit seiner Lehrzeit bei Borrosch \& André in Prag.

Aufgrund seiner Erfahrungen in der Buchhändlerbranche in der Heimat und im Ausland, also einer fast neunjährigen Praxis, mit Zusagen einiger Fachkollegen, ihm Anleihen zu gewähren, und mit konkreten Namen seiner Kommissionäre (z.B. der Arnoldschen Buchhandlung in Leipzig, von Jasper in Wien oder HöLzels , heimatlicher' Buchhandlung Borrosch \& André in Prag) zweifelte er kaum, befriedigende Resultate seines Unternehmens zu erzielen. ${ }^{4)}$

\section{Eduard Hölzels Buchhandlung in Olmütz}

Bereits am 12. September, nachdem er die Summe von 100 Gulden als sogenannte Inkorporationsgebühr beglichen hatte, erhielt er eine Bewilligung zum Errichten eines Ladens mit Büchern und Kunstgegenständen (Rosenbaum 1969, S. 4). Die Eröffnung eines Geschäfts mit Büchern, Kunstgegenständen und Musikalien unter dem Firmennamen Eduard HöLZEL wurde amtlich mittels eines Erlasses mit dem Datum der Firmengründung vom 13. September 1844 kundgemacht. Das Dokument wurde unter anderen mit der Unterschrift des Zeugen Alois Skarnitzel, eines Druckers aus Olmütz, bekräftigt, und die Firmenerklärung wurde beim K.k. Merkantil- und Verkehrsgericht in Brünn protokolliert und später auch in die Firmenakte des K.k. Landes- und Handelsgerichtes zu Olmütz eingetragen. Das Olmützer Ladengeschäft sollte ursprünglich seine ersten Kunden bereits am 1. Oktober begrüßen, tatsächlich erfolgte die Eröffnung aber erst am 15. Oktober 1844.

HöLzel gründete somit in seinem 27. Lebensjahr auf dem Oberen Ring in Olmütz im Hause Nr. 85) eine Sortimentsbuchhandlung, also ein Geschäft mit Büchern, Schriften und Druckerzeugnissen verschiedener Fachrichtungen und unterschiedlicher Auflage. Aus heutiger Sicht bot seine Buchhandlung Literatur ohne Unterschied des Genres.

HöLzels Unternehmertalent sowie seine solide Ausbildung in der Branche, sein Überblick und umgänglicher Charakter, halfen ihm wohl die anfänglichen Schwierigkeiten zu überwinden, und die neue Buchhandlung fing zwar langsam, aber sicher an zu florieren. Während weniger Jahre wurden Mitglieder des erzbischöflichen Domkapitels, Angehörige des mährischen Hochadels, vermögende Gutsbesitzer wie auch städtische Honoratioren zu Hölzels Kunden (Lindemann 1899). Schon von Anfang an gehörte zum Beispiel der Bankier Karl Anton Primavesi zu Hölzels Freunden und wohl auch Mäzenen.

4) ZAO, Krajský soud Ol.I (NAD 1465) Firemní spisy, Teil II. Ed. Hölzel Buch-, Kunst- und Musikalienhandlung VII 1863-1913/ Ol24 (Hilfsnr. 596, Inv. Nr. 866, Sign. JdV24)

5) Das Haus Nr. 8 mit HöLzels Buchhandlung stand bis 1908 ursprünglich auf dem Oberen Ring an der Stelle des heutigen Ladens Gran Moravia. In diesem Jahre wurde es niedergerissen und durch einen Neubau der Direktion der Kreditbank und des Café Grand ersetzt. 
Der Buchhändler erinnerte sich an seine Anfänge als Unternehmer in der Vorrede zur „Geschichte der königlichen Hauptstadt Olmütz“ von Willibald MülLER, wo er berichtet: „Als ich vor 37 Jahren, im Herbste 1844, in Olmütz meine Buchhandlung eröffnete, kannte ich daselbst niemanden außer einem mir verwandten Offizier und es gehörte wohl einiger Muth dazu, um mir in der fremden Stadt eine Existenz zu gründen. Aber schon nach wenigen Wochen kamen mir die gebildeten Bewohner von Olmütz und Umgebung mit so viel Wohlwollen und Vertrauen entgegen, daß ich mich bald an dem Gedeihen meines Geschäftes erfreuen und später die Herausgabe größerer Verlags-Unternehmungen wagen konnte.“ (MÜLLER 1882, unnummerierte Seite nach der Einleitung)

\section{Buchhändler, Verleger, literarisches Zentrum}

Sobald der Revolutionssturm des Jahres 1848, welcher unter anderem die Pressefreiheit mit sich brachte, Mähren umbrauste, gründete Eduard HöLzEL in Olmütz eine liberale Zeitung mit dem Titel Neue Zeit. Das Blatt wurde in kurzer Zeit sowohl in Mähren als auch in Österreichisch-Schlesien beliebt.

Die Olmützer Buchhandlung versorgte zu dieser Zeit nahezu ganz Nordmähren mit Büchern und unterschiedlichen Schriften. Um die steigende Nachfrage zu befriedigen, errichtete HöLzel Filialbuchhandlungen seines Geschäfts auch in anderen mährischen Städten. Im Jahre 1849 entstand eine Filiale in Neutitschein [Nový Jičín], später, im Jahre 1857 in Mährisch Ostrau [Moravská Ostrava], 1858 in Mährisch Schönberg [Šumperk], 1862 in Sternberg [Šternberk], 1863 in Ungarisch Hradisch [Uherské Hradiště], 1880 in Prerau [Přerov] und Kremsier [Kroměříž] (Heller 1890, S. 60).

Sein Bücherladen wurde bald zum Mittelpunkt aller Literaturfreunde von Olmütz und trug zum Vertiefen des Literaturinteresses der Stadtbürger bei. HöLzEL verband seine verlegerischen Anfänge mit zahlreichen Buchdruckern und Unternehmern aus Olmütz und aus Mähren (HeLLER 1890, S. 60). Bald nach seiner Niederlassung pflegte er junge Talente aus verschiedenen Fächern zu treffen, welche er zum wissenschaftlichen und geistigen Schaffen anspornte. Er war begabt, in seinen regelmäßigen Besuchern deren Fähigkeiten und Talente zu entdecken. Zu seinen Kunden und späteren Freunden gehörten zum Beispiel der künftige Professor der Philosophie Carl STumpF oder der Geograph und Orientalist Wilhelm ToMAscheK, weiters auch der Dichter, Komponist und künftige Ministerialrat Eduard ScHöN oder der Jurist und Politiker Ignaz MAснAneK, welche alle größtenteils durch ihr Studium oder ihre berufliche Laufbahn mit Olmütz verbunden waren. Im Jahre 1853 besuchte der deutsche Astronom Julius Schmidt oft die Familie HöLzel. Zu den häufigen Gästen gehörte auch der Botaniker Karl Heller (Mährisches Tagblatt 10.10.1894, S. 3).

Außer dass HöLzel gern verschiedenen Intellektuellen, Künstlern und Gelehrten begegnete, war er auch wegen seines umfangreiches Wissens, seines milden und freundlichen Charakters und netten Humors ein sehr gefragter Gesellschafter. Er war seinen Freunden oft ein Ratgeber. Die harmonische Ehe und ein glückliches Familienleben trugen sicher zu seinem innerlichen Behagen bei. Er ehelichte am 26. Februar 1848 in Omlütz Hedwig NiemanN (1827-1881), Tochter des pensionierten

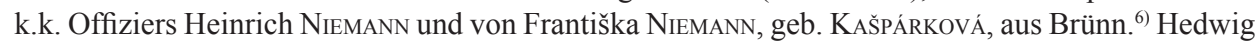
war außerdem Nichte der Ehefrau von Wilhelm von EnGEL, einem bedeutenden Händler aus Olmütz, und somit auch Cousine des späteren Bürgermeisters von Olmütz Josef ENGEL (Mährisches Tagblatt 10.10.1894, S. 1-5). Eduard hätte laut den Aussagen seiner Zeitgenossen wohl keine bessere Gat-

6) ZAO-Ol, katolická matrika (Římskokatolická fara v Olomouci-Sv. Michal), Sign. O V 12, Inv. Nr. 5643, $1823-1860$ 
tin auswählen können. ${ }^{7)}$ Sie war eine liebeswürdige, nette und liebevolle Ehefrau und später auch Mutter von vier Kindern, außerdem besaß sie sowohl Anmut als auch wunderbare Charakter- und Geistesvorzüge (Lindemann 1899). Eduard fand in ihr eine Gattin, die sich in Literatur und Kunst auskannte. So war Eduards Ehefrau Hedwig daran beteiligt, dass im Hause HöLzEL am Oberen Ring Leserfreunde, Literaten und Gelehrte zu Literaturabenden und zu Diskussionen über den Stand der damaligen deutschen, aber auch tschechischen Literatur zusammentrafen (LECHNER 1886, S. 3).

Man erfährt fast jedes Mal aus den lückenhaften Abhandlungen über HöLzEL, dass er ein ausschließlich deutscher Buchhändler und Verleger gewesen sei. Er bot aber in seinem Laden auch tschechische Literatur an; fast alle Leiter seiner Filialbuchhandlungen waren Tschechen, und der Umstand, dass die Mehrheit seines Angebotes die deutschsprachige Literatur bildete, hing von der Nachfrage ab. Genauso wie für jeden Kaufmann war auch für HöLzel der Profit wichtig. Die Erträge wurden bei HöLzel jedoch in der Regel in neue verlegerische Projekte weiterinvestiert. HöLzEL war in keiner Weise negativ nationalistisch beeinflusst, es ging ihm vornehmlich um die Qualität der bei ihm verlegten Werke und nicht um deren Sprache. Der Bedarf an deutschsprachigen Büchern war in Mähren stets groß, die deutschen Titel wurden sowohl von deutschen als auch tschechischen Kunden nachgefragt. HöLzels Anliegen war es, durch seine Herausgebertätigkeit die Leser ohne Rücksicht auf deren Nationalität, Sprache oder Konfession mit Titeln zu versorgen. Andererseits musste er als Unternehmer und Händler bei einigen Projekten Risiken in Erwägung ziehen.

Dass der Verleger die tschechische Literatur nicht ablehnte, zeigt sich auch daran, dass er im Jahre 1846 die tschechische Übersetzung der Fabeln des Bidpai von F.M. KLÁcel herausgab und bereits ein Jahr davor den vierten Teil der tschechischen Sagen aus Mähren und Schlesien [Slezsko] des mährischen Nationalerweckers Matěj MıкšíčEK drucken ließ. Dieser Schriftsteller und Journalist wirkte etwa 15 Monate im Olmützer Verlag; vom Januar 1845 bis April 1846 kümmerte er sich um tschechische Kunden und tschechische Bücher. Beide Kommis von HöLzel sowie sein Diener sprachen lediglich Deutsch, und wenn Eduard HöLzel, der wohl Tschechisch fließend beherrschte, nicht im Geschäft war, gab es niemanden, der sich den tschechischen Kunden widmen und mit ihnen auf Tschechisch reden konnte. ${ }^{8}$

\section{Schulbuch- und Kunstverlag}

HöLzel setzte die Herausgabe tschechisch geschriebener Literatur auch in den nächsten Jahren fort, darüber hinaus engagierte er sich sehr bei der Herausgabe von Schulliteratur. Im Jahre 1863 bereitete er VANĚKS „Stručná vlastivěda Moravy a Slezska“ vor, im Jahre 1867 erschien die deutsche Schulgrammatik „Mluvnice německá pro nižší třídy škol středních“ von František MARTinÁK bei ihm. Aus der Feder dieses Autors gab Hölzel weiterhin das deutsch-tschechische Übungsbuch

7) Das Ehepaar HöLzel hatte insgesamt acht Kinder, ein Kind wurde leider tot geboren. Von diesen acht Kindern erreichten nur vier das Erwachsenenalter: Hugo Josef (12.02.1852-1895), Adolf Richard (13.05.18531934), Emma Maria Antonia (geb. 15.06.1855) und Hedwiga Amalia (geb. 18.12.1857). Der erstgeborene Sohn Adolf Wilhelm verstarb nach einem Jahr (4.06.1850-16.10.1851), Eduard Heinrich nach einem nicht vollendeten halben Jahr (10.10.1856-05.05.1857), Eduard Emil nach einem Jahr (6.05.1859-28.05.1860). Das letzte Kind Rosa Margarita Theresia wurde am 19.10.1863 in Olmütz geboren. Weil aber die Familie im Jahre 1871 nach Wien umzog, verfügt man über keine Auskunft über ihren Tod, sie erreichte aber auch nicht das Erwachsenenalter.

8) MiKŠÍčEK bewährte sich wohl in der Arbeit, denn HöLzel stellte ihm ein Empfehlungsschreiben für seinen neuen Arbeitsgeber, den Buchhändler WIMMER in Brünn, aus (FIŠER 1993). 
„Č́ítací a cvičebná kniha jazyka německého a českého“ (1869) heraus. Das lateinische Übungsbuch „Latinská cvičební kniha pro prvou třídu česko-slovanských gymnáziii“ von 1868 war ein Werk des Olmützer Professors Alois VANíčEK. Die tschechischen Bücher wurden für Hölzel zuerst in Olmütz bei Alois ŠKARNICL gedruckt, später bei František SLAVík. Der unternehmungslustige Kaufmann verwertete seine Erfahrungen mit der Herausgabe von Lehrbüchern viele Jahre später bei der Herstellung von Schulwandtafeln. Diese wurden zu international beliebten Artikeln, verkauften sich noch lang nach Hölzels Tod äußerst gut, und noch weit nach 1900 fanden sie Absatz in England, Frankreich, Deutschland, Russland, Schweden, Australien, Japan, in der Schweiz, in den Niederlanden und den USA (KLEE 2016).

Wie schon erläutert, neigte der Vater von Eduard HöLzel zur Kunst und er übertrug dieses Interesse auch auf seinen ältesten Sohn. Eduard fing bereits in den ersten Jahren seiner selbstständigen Tätigkeit an hochgeschätzte Werke herauszugeben, welche dank ihrer künstlerischen Ausführung großes Aufsehen in der Fach- und Laienöffentlichkeit erregten und trotz hohen Preises problemlos vertrieben wurden. So gab er im Jahre 1856 eines der ersten Prachtwerke heraus, ein großes illustriertes Buch über Forstkulturpflanzen Deutschlands von Ferdinand FISCALI, einem Fachmann für Forstwesen und Pädagogen (siehe FisCALI 1856).

In den Jahren 1856-1860 erschien der bis heute geschätzte Lithographienzyklus von böhmischen, mährischen und schlesischen Städten, Burgen, Schlössern und Naturdenkmälern, der in verschiedenen Varianten zu erwerben war. Das Angebot reichte von billigeren, nur getönten Blättern bis zu den kostspieligen kolorierten Editionen. Das monumentale Werk stellte dank seines Herausgebers würdevoll die Kronländer Böhmen [Čechy], Mähren und Schlesien als schöne und unvergessliche Bestandteile der Habsburgermonarchie dar (siehe Hölzel 1857-1860).

Die Drucklegung der Publikation über Eichen des namhaften Botanikers Theodor Kотschy im Jahre 1858 fand ebenfalls großen Anklang. Котsснуs Werk wurde in der zweiten Hälfte des 19. Jhs. für eines der schönsten Druckwerke aus dem Fachbereich der Botanik gehalten (siehe Kотsсну 1858).

Hölzel erhielt für sein nächstes botanisches Werk, das allerdings erst nach 1860 in Wien herausgegeben wurde, sogar eine seiner zahlreichen Auszeichnungen, eine Brillant-Busennadel von Kaiserin Elisabeth als Beweis ihrer Anerkennung. Es handelte sich um ein Werk mit Gedichten von Johann Nepomuk VogL und Chromlithographien nach den Originalen von Andreas LACH, das den Titel Blumen der Heimath in Bild und Lied trug. ${ }^{9)}$

Hölzel ließ Werke mit reicher künstlerischen Ausschmückung zuerst in Berlin in der lithographischen Anstalt von Wilhelm LoEILLOT oder in Wien in der lithographischen Anstalt des Grafikers Karel HoŘEGŠí anfertigen. Er übernahm schlussendlich im Jahre 1861 den Betrieb des Zweitgenannten, woraufhin er auf eigene Kosten und mit neuem Enthusiasmus viele Genre- und Landschaftsbilder druckte, die er nach Originalvorlagen von bekannten Münchner oder Wiener Meistern erschaffen ließ. Die Chromlithographien aus HöLzels Atelier hatten lange Zeit keine Konkurrenz und galten als das Beste nicht nur in der Österreichisch-Ungarischen Monarchie, sondern auch in Deutschland, Holland oder in der Schweiz.

HöLzEL gab außerdem während der 1860er und späten 1870er Jahre zahlreiche Hilfsmittel zur Technik der Chromolithographie heraus. Es handelte sich insbesondere um historische Bilder und Schultafeln, religiöse Bilder oder Bilder reiseberichtenden Charakters, die international vertrieben

\footnotetext{
9) Das Werk befindet sich leider nicht in den Beständen der Wissenschaftlichen Bibliothek in Olmütz, einige der Tafeln kann man im Fonds der Prager Nationalbibliothek [Národní knihovna v Praze, NKP] finden, das ganze Werk kann in Wien eingesehen werden. Es handelte sich um die Arbeit „Blumen der Heimath in Bild und Lied: Der erste Frühling, wilde Rosen, Wald, Wiese, Feld und Alpe“, Dichtung von Joh[ann] Nep[omuk] VoGL. Oelfarbendruck nach den Originalen von A[ndreas] LACH, Wien, Eduard Hölzel. [ca. 1860]. 9 Bl., 18 Taf. (LiNDEMANN 1899).
} 
wurden. Englische Missionare nutzten HöLzels religiöse Bilder auf ihren Reisen im Namen des Glaubens, Abbildungen aus dem Sudan oder dem Kongo dienten wiederum den Abenteurern und Reisenden durch Afrika (Heller 1890, S. 60).

\section{Der Weg zum Kartenverlag und geographischen Institut}

Außer dass sich Hölzel mit großem Interesse und intensiver Pflege der Herausgabe von Publikationen mit reichem Bildschmuck widmete, gab es noch einen Bereich seines beruflichen, aber auch persönlichen Interesses, der für ihn erstrangig war und wohl den wichtigsten Teil seiner Arbeitskraft beanspruchte. Eduard HöLzEL erkannte nämlich bald aufgrund zahlreicher Anregungen, die besonders aus Lehrerkreisen kamen, aber vor allem dank seiner Umsicht und Vorliebe, dass auf dem Gebiet der Österreichisch-Ungarischen Monarchie wichtige Lehrmittel besonders für den Geographieunterricht fehlten. Er hielt Geographie und Kartographie für einige der wichtigsten erdkundlichen Bereiche, weil ohne Landkarten keine wirtschaftlichen, botanischen und politischen Fragen beantwortet werden konnten. HöLzEL fand deshalb im Bereich der Kartographie ein breites Wirkungsfeld vor, das allmählich zu seinem wichtigsten Anliegen wurde, ja fast zu seiner Lebensaufgabe.

HöLzel gründete etwa zur selben Zeit, als er das Kunstinstitut von HoŘEGŠś in Wien übernahm, also im Jahre 1861, in der österreichischen Hauptstadt das Geographische Institut, das erste und für lange Zeit wichtigste private Unternehmen dieser Art in Österreich. Er erwarb zu diesem Zweck ein Haus im 4. Bezirk (Luisengasse, heute Mommsengasse Nr. 5), wo er das lithographische und geographische Institut und die Druckerei versammelte. Dorthin übertrug er auch allmählich den Sitz seines Verlages. Im Jahre 1871 zog er auf Dauer nach Wien, wobei die Werke seines Verlagshauses sowohl in Wien als auch in Olmütz erschienen.

HöLzEls Unternehmen wies seitdem klare Attribute eines Fachverlages auf, der sich in erster Linie auf die Herausgabe von Geographielehrbüchern, Landkarten und Atlanten spezialisierte. An zweiter Stelle konzentrierte er sich auf die Herausgabe von Fachpublikationen, insbesondere auf prachtvolle botanische Werke, weiters auf Lehrbücher und Reiseberichte, heimatkundliche und historische Publikationen und Handbücher. Den kleinsten Bestandteil seiner verlegerischen Arbeit stellten die Zeitungen und Zeitschriften dar.

Er trat dank persönlicher Beziehungen und bisheriger wertvoller Produktion häufiger in Kontakt mit österreichischen Wissenschaftern und Gelehrten, zu denen zum Beispiel die Geologen Eduard Suess und Franz Hauer, der Geodät und Kartograph Karl KoŘISTKa oder der Statistiker und Kartograph Josef ErBEN gehörten. Im Jahre 1858 befreundete sich Eduard HöLzEL mit dem Gymnasialprofessor, Erdkundler und Kartographen Blaž Kocen, welcher mit Begeisterung Hölzels Plan aufnahm, einen österreichischen Schulatlas herauszugeben. Der erste Schulatlas in der Habsburgermonarchie erschien 1861, erlebte einen Riesenerfolg, wurde weit verbreitet und wird mit vielen Abänderungen bis heute gedruckt (BRATEC MrVAR et al. 2011).

Man setzte auch nach Eduards Tod die leitende Marktstrategie des Verlages fort, also die Herausgabe von Landkarten. Anfang des 20. Jhs. wurde das Sortiment um geläufige Straßenkarten für Autofahrer erweitert, und als Verlag, der auf Schulbücher und Atlanten spezialisiert ist, hat die Firma bis heute Erfolg. Der geht auf seinen Gründer Eduard HöLzel zurück, welcher rechtzeitig die Marktlücke erkannte und sie bald danach durch sein Wirken füllte. Sein Verlag deckte die Fachgebiete Geographie und Kartographie ab und leistete diesen Fächern einen wichtigen Dienst (FuHs 1996, S. 37). Die österreichische Kartenproduktion konnte sich dadurch von der deutschen verselbstständigen. 


\section{Resumée}

Eduard HöLzel war ein Mann, dessen Bedeutung für die Entwicklung des österreichischen, aber auch mährischen Buchhandels außerordentlich war und dessen Verdienste zumindest nach seinem Tod allgemein bekannt wurden. Nicht nur seine Kollegen, sondern auch der Kaiser hielten ihn in Ehren und schätzten ihn hoch. HöLzEL war ein nicht nur in seinem Fach gebildeter, fähiger und unglaublich aktiver und tatkräftiger Mensch, welcher keine Herausforderung fürchtete und oft Risiken einging. Im gesellschaftlichen Umgang war er außerordentlich leutselig. Er zeigte reges Interesse für Kunst und Musik, traf gern verschiedene Künstler und Gelehrte, und sein Haus wurde von seltener Gastfreundlichkeit geprägt. Die Beziehungen mit ihm waren immer inspirierend und anregend und er gewann durch seine fröhliche Lebensanschauung sowie durch seinen freundlichen und klugen Humor viele Freunde. Er ging mit seinen Nächsten immer sehr ehrlich um und war allen seinen Freunden ein aufrichtiger und gefälliger Ratgeber.

Dass er die Stadt Olmütz auswählte, wo er seinen ersten eigenen Laden eröffnete, stellte den wichtigsten Schritt seines Lebens dar. Er selbst dachte so zurück: „Nachdem ich 1860 mein Wiener Geschäft gründete und in Folge seiner Ausbreitung genöthigt war, im Jahre 1870 mein Domicil nach Wien zu verlegen, verließ ich Olmütz ungern, wo ich durch beinahe $1 / 4$ Jahrhundert neben mancherlei Sorgen und Mühen recht glückliche Zeiten verlebt hatte, wo mir ein reines, schönes Familienglück erblüht war. Wohl mußte ich befürchten, daß durch meine längere Abwesenheit von Olmütz ein Rückgang meines dortigen Geschäftes erfolgen könnte, aber durch die so lange Jahre hierauf verwendete Sorgfalt blieben nicht nur alle Gönner und Abnehmer meiner Buchhandlung derselben getreu, sondern es trat zu meiner Befriedigung statt einer Verminderung eine erhebliche Erweiterung meines Umsatzes in Olmütz ein ... Es war daher nur ein Gefühl der Dankbarkeit, das mich zur Herausgabe einer ,Geschichte der königl. Hauptstadt Olmütz‘ veranlaßte, um meinen geehrten Mitbürgern einen, wenn auch nur geringen Beweis meiner treuen Anhänglichkeit an diese mir so lieb gewordene Stadt zu liefern.“(GraESER \& MÜLLER 1894, S. 2f.)

\section{Literaturverzeichnis}

Bratec Mrvar R., Birsak L., Fridl J., Kladnik D., Kunaver J. (2011), Kocenov srednješolski atlas kot didaktična prelomnica [Kocens Schulatlas als didaktischer Wendepunkt]. Ljubljana, Založba.

Graeser C., Müller W. (1894), Olmütz im Jahre 1894: Denkschrift aus Anlass des Ankaufes der Festungsgründe durch die Stadtgemeinde. Olmütz, Ed. Hölzel's Buchhandlung.

FIšER Zd. (1993), Poznámky knihkupeckého mládence o Olomouci roku 1845 aneb Matěj Mikšíček svým láskám [Aufzeichnungen eines Buchhändlerjungen über Olomouc im Jahr 1845 oder die Liebe von Matěj Mikšíček]. In: Zprávy Vlastivědného muzea v Olomouci, 270, S. 43-52.

FisCALi F. (1856), Deutschlands Forstcultur-Pflanzen. Olmütz, Verlag von Eduard Hölzel.

Funs P. (1996), Fünf land- und forstwissenschaftliche Fachverlage. Ein Beitrag zum Verlagswesen in Österreich. Diplomarbeit, Universität Wien.

Heller H. (1890), Mährens Männer der Gegenwart: Biographisches Lexikon. 4. Theil/Grossgrundbesitzer, Land- und Forstwirthe, Commerzielle. Brünn, s.n.

Hölzel A., Lemmé M. (1933), Gedanken und Lehren. Zusammengestellt und mit einer biographischen Einleitung herausgegeben von Marie Lemmé. Stuttgart - Berlin, Deutsche Verlags Anstalt.

HöLzEl E. (Hrsg.) (1857-1860), Malerisch-historisches Album von Mähren und Schlesien. Olmütz, Eduard Hölzel. 
KLEE A. (2016), Viribus unitis? Networking im Vielvölkerstaat am Beispiel der Verlegerfamilie Hölzel. In: Migration und Innovation um 1900. Perspektiven auf das Wien der Jahrhundertwende, S. 425-458. Wien - Köln - Weimar, Böhlau.

Kinauer R. (1972), Hölzel, Eduard. In: Neue Deutsche Biographie, 9, S. 340-341. - https://www. deutsche-biographie.de/gnd130833312.html\#ndbcontent

Koтschy Th. (1858), Die Eichen Europa's und des Orient's: Gesammelt, zum Theil neu entdeckt und mit Hinweisung auf ihre Cultur-Fähigkeit für Mittel-Europa etc. etc. Wien - Olmütz, Eduard Hölzel's Verlags-Exped.

LechNer R. (1886), Eduard Hölzel [Nekrolog]. In: Mährisches Tagblatt, 7, 3, 05.01., S. 3-4. - http:// anno.onb.ac.at/cgi-content/anno? aid $=m t$ tbdatum $=18860105 \& z o o m=33$

Lindemann H. (1899), Eduard Hölzel. In: Oesterreichisch-ungarische Buchändler-Correspondenz, 40, 47, 22.11., S. 552-553. - http://anno.onb.ac.at/cgi-content/anno?aid=obc\&datum $=18991122 \&$ zoom $=33$

Mährisches Tagblatt (1894), Zum 50jährigen Jubiläum der Firma Eduard Hölzel in Olmütz und Wien (15. October 1844-1894). 15, 232, 10.10., S. 3. - http://anno.onb.ac.at/cgi-content/ anno? aid $=m t$ tb datum $=18941010 \& z o o m=33$

MüLLER W. (1882), Geschichte der königlichen Hauptstadt Olmütz. Wien - Olmütz, Ed. Hölzel.

NEŠPOR V. (1936), Dějiny Olomouce [Geschichte von Olmütz]. In: Vlastivěda moravská: II. Místopis Moravy, S. 58. Brno, Musejní spolek.

Puš I. (1918), Starosta Karl Brandhuber a národní život v Olomouci za jeho úřadu (1896-1918). Př́spěvek k tématu vzájemného soužití českého a německého obyvatelstva na Moravě před rokem 1918 [Bürgermeister Karl Brandhuber und das nationale Leben in Olmütz während seiner Amtszeit (1896-1918). Beitrag zum Thema der Koexistenz der tschechischen und deutschen Bevölkerung in Mähren vor 1918]. Diplomarbeit, Universität Olmütz.

Rosenbaum Brüder (1969), Ed. Hölzel 1844-1969: zum 125jährigen Bestand des Hauses am 15. Oktober 1969. Wien, Eigenverlag.

VoIT P. (2008), Encyklopedie knihy: starší knihtisk a př́ibuzné obory mezi polovinou 15. a počátkem 19. století: papír, písmo a písmolijectví, knihtisk a jiné grafické techniky, tiskaři, nakladatelé, knihkupci, ilustrátoři a kartografové, literární typologie, textové a výtvarné prvky knihy, knižní vazba, knižní obchod [Lexikon des Buches: älterer Buchdruck und verwandte Gebiete zwischen dem 15. und frühen 19. Jh.: Papier, Schreiben und Briefeschreiben, Buchdruck und andere graphische Techniken, Drucker, Verleger, Buchhändler, Illustratoren und Kartographen, literarische Typologie, Text- und Kunstelemente des Buches, Buchbindung, Buchgeschäft], 2. Aufl. Praha, Libri, Královská kanonie premonstrátů na Strahově.

Vybíral B. (1931), Romualdovi Prombergrovi k pětasedmdesátce. Olomouc. - http://katalog. ahmp.cz/pragapublica/permalink?xid $=1$ F40811123A911E08F90005056C00008\&scan $=1$ 